\title{
Fanny Hill, la pornogirafía y la novela sentimental: el eslabón faltante en la gesta de la novela inglesa dieciochesca ${ }^{1}$
}

\section{Fanny Hill, Pornography, and the Sentimental Novel: The Missing Link in the Making of the Eighteenth-Century English Novel}

\author{
ELENA DEANDA-CAMACHO \\ Departamento de Lenguas \\ WASHINGTON COLLEGE | Estados Unidos \\ Contacto: edeanda2@washcoll.edu
}

\section{Resumen}

Este artículo analiza la manera en la cual la novela inglesa Fanny Hill (1748) de John Cleland sintetiza el idealismo cervantino, propio de la novela sentimental, y el realismo, heredero de la picaresca femenina. Al situar esta obra en la gesta de la novela dieciochesca inglesa, especialmente frente a las obras de Samuel Richardson y en constante diálogo con el legado picaresco y cervantino, Fanny Hill emerge como una novela compleja, metaficticia y reflexiva. En su reflexividad, Cleland se enfoca en analizar los mecanismos de la novela en general y de la novela pornográfica en particular. Los mecanismos que se destacan son la reflexión sobre el ejercicio literario, el registro lingüístico y la recepción. Sobre todo, Fanny -como "narradora" - se detiene a analizar con detalle el savoir faire de la novela pornográfica en la cual el tema central del sexo, en cuanto mecánico y repetitivo, exige una narrativa mecánica y repetitiva. Finalmente, el artículo destaca la complicada agencia simbólica, literaria, económica y de género, que despliega la "narradora" Fanny

${ }^{1}$ Este artículo fue patrocinado por la Faculty Enhancement Grant de Washington College y el Summer Research Grant de la North East Modern Language American (NEMLA). Asimismo, contó con el apoyo de la British Library en Londres, Reino Unido. 
ante otras protagonistas de la novela inglesa, como Pamela o Clarissa. Al enfatizar la síntesis que la novela hace del idealismo y del realismo, así como su constante reflexividad, arguyo que Fanny Hill debe ser considerada más que una obra exclusivamente pornográfica y entrar en el canon de la novela inglesa del dieciocho.

\title{
Palabras clave
}

Fanny Hill, Quijote, pornografía, Richardson, Pamela

\begin{abstract}
This article analyzes how the English novel Fanny Hill (1748) by John Cleland synthesizes the Cervantine idealism, characteristic of the English sentimental novel, with Spanish realism, stemming from female picaresque. By situating this novel in the making of the eighteenth-century English novel, especially in its dialogue with Samuel Richardson's work and the Cervantine legacy, I aim to demonstrate that Fanny Hill is a metafiction, or a deeply complex and reflexive novel. When displaying narrative reflexivity, Cleland analyzes the mechanics of the narrative genre in general and, in particular, of the pornographic novel. The mechanisms that he puts into place are the constant reflections on the literary craft, on the linguistic register, and on his audience. Fanny, as the "narrator", focuses on the savoir faire of the pornographic novel that, by being mechanical and repetitive, requires a mechanical and repetitive narrative. Finally, the article highlights the symbolic, literary, economic, and gendered agency embodied by Fanny $v i s-a ́-v i s$ other female protagonists, such as Richardon's Pamela and Clarissa. By focusing on its synthesis of idealism and realism, and emphasizing its reflexivity, I argue that Fanny Hill is a text to be withdrawn from the private cases of pornography and to be included in the eighteenth-century English canon.
\end{abstract}

\section{Keywords}

Fanny Hill, Quixotic, pornography, Richardson, Pamela 


\section{El legado cervantino y picaresco en la novela inglesa del dieciocho}

E

613, entre las dos partes de El ingenioso hidalgo don Quijote de la Mancha, Miguel de Cervantes Saavedra (1547-1616) publicó Las novelas ejemplares, una colección de novelas ejemplares que tenían el objetivo de cumplir con el imperativo horaciano del delectare et prodesse. Estas novelitas se volverían un modelo del género narrativo que Cervantes casi de manera inadvertida estaba gestando. Entre ellas se destaca La fuerza de la sangre, la historia de una joven hidalga y pobre quien, tras haber sido raptada y violada por un joven hidalgo rico, experimenta la vergüenza privada, un embarazo no deseado y numerosas peripecias hasta que hacia el final de la novela se reencuentra con el hombre que la violó, se casa con él, recupera su honra y encuentra "remedio" a su pasada ignominia.

Leer La fuerza de la sangre en la época del \#metoo nos enfrenta a una miríada de problemas, sobre todo al intentar poner en contexto esta novela con el idealismo de la época y el código de la honra española. Estas circunstancias son condiciones necesarias para explicar ese final problemático: el matrimonio con su violador (véase Boruchof, 2016; Lefere, 1994; Mayer, 2005). Sin duda, pese a que Cervantes dio un gran protagonismo a las mujeres en su obra, el autor salmantino no pudo escapar a la misoginia de su época y mucho menos al ethos de violencia sexual que ha determinado el patriarcado occidental pre- y moderno. El final de $L a$ fuerza de la sangre muestra con crudeza ese ethos de violencia sexual ${ }^{2}$ que permite que un violador tenga acceso, primero, al cuerpo-objeto femenino y, después, a la belleza y la potencia procreadora de ese mismo cuerpo-objeto con fines de reproducción genética y social. Como he argumentado en otro lugar, no se puede continuar pontificando un autor sólo por su éxito literario sin poner en crisis el ethos de su obra y de su tiempo (Deanda-Camacho, 2017: 21-33). Con todo, ethos de lado, en sus Novelas y en el Quijote Cervantes sembró el germen de la narrativa europea y,

${ }^{2}$ La socióloga Patricia Hill Collins (2005) emplea el término de "ethos de violencia sexual" (189) para explicar cómo la lucha social se batalla en el espacio del cuerpo y la sexualidad - en otras palabras, cómo nuestra cultura proyecta la sexualidad mediada por la violencia y la violencia mediada por la sexualidad-. 
por extensión, occidental. Su narrativa se volvió el modelo de la ficción en los siglos venideros, precisamente por esa mezcla exitosa de idealismo y realismo, de novela caballeresca y picaresca, que aunados a la cualidad reflexiva y metaficticia de su obra, lo han vuelto hasta la fecha uno de los parangones de la vanguardia narrativa.

En el siglo dieciocho el legado cervantino experimentó un redescubrimiento, especialmente en Inglaterra y Francia. Como muestras cabe señalar dos obras, The Female Quixote (1752) de Charlotte Lennox (1730-1804) y Facques le fataliste (1796) de Denis Diderot (1713-1784), dos reescrituras del Quijote y Sancho, respectivamente. El legado cervantino, como nota Edward Friedman (2006), se leyó en Europa bajo dos vertientes: por un lado, enfocándose en el idealismo propio del quijotismo y, por el otro, en el realismo crudo y humorístico de la picaresca. El idealismo en El Quijote $(1605,1615)$ provenía ya de la novela de caballería del Medievo, a su vez heredera del amor cortés y la novela cortesana. La picaresca, por su parte, es de suyo germen de la narrativa universal, pues la primera novelita en Occidente se publicó en España bajo el nombre de Lazarillo de Tormes (1554). Esta novelita anónima abriría paso a una saga de novelas picarescas en los siglos subsecuentes, desde el Guzmán de Alfarache (1599-1604) de Mateo Alemán (1547-1615) a La vida del buscón (1626) de Francisco de Quevedo (1580-1645), entre las obras españolas más sobresalientes. Es de notar que la picaresca como subgénero también se bifurcaba en dos: la picaresca masculina y la femenina. Mientras que la primera se enfocaba en criminales e impostores, la segunda hablaba de prostitutas o mujeres de baja ralea que lograban engañar a los hombres para proveerse de sustento (véanse Delfín Val, 2008; Zafra, 2009). Entre las novelas picarescas femeninas más famosas figuran $L a$ hija de Celestina (1612) de Alonso Salas Barbadillo (1580-1635), Las harpías de Madrid (1631), Teresa Manzanares y La garduña de Sevilla (1642) de Alonso de Castillo Solórzano (1584-1647), entre otras. Todas ellas eran herederas de la Tragicomedia de Calisto y Melibea o Celestina de Fernando de Rojas publicada en 1499, la matrix de los textos sobre la prostituta y que yo llamo pornológicos (véase Deanda Camacho, 2020). A diferencia de la picaresca masculina, la picaresca femenina subrayaba el aspecto sexual de las mujeres pues era a partir de su belleza, sus capacidades de seducción y su cuerpo, que estas mujeres llevaban a cabo sus estafas. 
Como muchos críticos han notado - entre ellos J. A. G. Ardila (2001a, 2001b), Pedro Javier Pardo García (1997), Brean S. Hammond (1998) y Susan Staves (1972), entre otros-, la novela del dieciocho inglés abrevó del legado cervantino, tanto del idealista como del picaresco. En este último rubro es evidente el préstamo de los motivos de la novela picaresca en novelas canónicas de la ficción inglesa como Moll Flanders (1722) de Daniel Defoe (1660-1731), Foseph Andrews (1742) y Tom fones (1749) de Henry Fielding (1707-1754) e incluso en Tristram Shandy (1759-67) de Laurence Sterne (1713-1768). En estas obras aparecen protagonistas de clase baja quienes, con diversos trucos, buscan ascender en la escala social. Desafortunadamente todos sus intentos son infructuosos pues las obras constantemente refuerzan la hegemonía, poniendo a estos personajes “en su lugar”. Más aún, como ha notado Edward Friedman (1987), en la novela picaresca el escritor se trasviste de estos personajes marginalizados y los “azota” doblemente pues añade a la violencia social la violencia simbólica al hacer que sus protagonistas se auto-ataquen o burlen de sí mismos. Las novelas picarescas, con todo, suelen crear espacios para la impunidad y la resistencia. Entre los intersticios del texto emergen, aunque de forma problemática, las voces de mujeres marginadas que desestabilizan el espacio literario. De esa manera tenemos, por ejemplo, a una Moll Flanders quien, aunque es pobre al principio, obtiene seguridad económica y un cierto ascenso social.

Es indudable que el idealismo cervantino decantó en la novela sentimental inglesa del siglo dieciocho, género en el cual se retomaba el imperativo horaciano de deleitar y enseñar. Aquí encontramos novelas que se enfocan en contar la vida de una mujer y llevan a menudo su nombre como título, en especial las obras seminales Pamela (1740) y Clarissa (1749) de Samuel Richardson (1689-1761). En estas novelas aparece como constante el formato epistolar, la ilusión de ofrecer una ventana a la psicología y la sensibilidad femeninas (pues "hablan" en voz de mujer) y el objetivo de arengar a la audiencia sobre el vicio y la virtud. De la misma manera que Voltaire o Jean Jacques Rousseau buscaban aleccionar a los hombres jóvenes con Cándide (1759) o Émile (1762), respectivamente, Samuel Richardson se enfocó en aleccionar a las mujeres jóvenes con Pamela y Clarissa. 
Como dice en el Prefacio de Clarissa, el texto busca “to caution” a los padres sobre su exceso de disciplina y a las jóvenes sobre el valor de la virtud. La ópera prima de Richardson, Pamela, publicada en 1740, inició esta empresa y su impacto fue tan importante que el satirista Henry Fielding se apresuró en escribir su parodia, Shamela Andrews, un año después. Lo mismo hizo Eliza Haywood en su crítica, aún más radical, Anti-Pamela (1741).

Si Pamela or the Virtue Rewarded de Richardson llegó a tener parodias o ripostas, es porque fue un best seller y ello le ha ameritado el título de la novela fundacional inglesa del siglo XVIII. Aquí es preciso recordar con Ian Watt (2001) cómo la novela como género experimentó durante este periodo un éxito comercial y público. El desarrollo de la producción mecánica en el campo de la imprenta acompañó el desarrollo del género narrativo. El éxito comercial de Pamela es la prueba. La historia es simple: Pamela, una doncella de quince años, le cuenta en epístolas a sus padres que es acosada por Mr. B., su máster o dueño, quien tarde o temprano la ataca sexualmente hasta que al final se casa con ella. Durante toda la obra Pamela narra la resistencia que ella opone a sus avances, su tragedia al perder la virtud que tanto guardaba y la eventual resolución positiva. Esta novela es reminiscente de $L a$ fuerza de la sangre en muchas maneras. Pamela, como la Leocadia cervantina, es una pobre y joven mujer que sufre el acoso y abuso sexual de un hombre poderoso. Al igual que Leocadia, Pamela encuentra al final su recompensa al casarse con su acosador y obtener la posición social que éste le procurará de ahora en adelante. Pamela y Leocadia son ejemplos femeninos porque denuncian y resisten el vicio, y mantienen una pureza y virtud inamovibles. En consecuencia, al final se ven recompensadas.

En la literatura inglesa del dieciocho Samuel Richardson a menudo se distingue como uno de los grandes vectores de la novela, seguido por Henry Fielding, Daniel Defoe, Tobias Smollet o Laurence Sterne (Beasley, 1976: 437). Pero poco o nada figura otro de los autores que creó uno de los grandes best sellers ${ }^{3}$ de la época,

${ }^{3}$ Sobre el alcance comercial de Fanny Hill en Inglaterra y Europa, véanse Darnton (1996) y Peakmam (2003). 
John Cleland, quien con su obra Fanny Hill (1748) no sólo reescribió la novela sentimental inglesa, sino que la combinó con la picaresca femenina creando un espacio en el cual tanto el idealismo como el realismo coexistían. En estas líneas traigo a cuento el legado quijotesco y picaresco para argumentar que frente a la novela fundacional Pamela de Richardson, la Fanny Hill de Cleland es una obra que debe considerarse esencial en la gesta de la novela inglesa (y europea por extensión) porque conjunta el idealismo quijotesco, el realismo picaresco y la reflexividad cervantina. Al conjuntar estos rasgos como característicos del devenir del género narrativo, Fanny Hill amerita su justo espacio en el proceso de canonización de la novela.

\section{Fanny Hill y Pamela como herederas del legado cervantino y picaresco}

Fanny Hill ha sido puesta en otra categoría dentro de la narrativa del dieciocho, la de la novela pornográfica. En la veta de la "tradición pornográfica", como la ha llamado Lynn Hunt (1996), Fanny Hill pertenece a un subgénero que es la autobiografía de la prostituta, subgénero cuyo origen se remonta a las novelas del siglo XVI. En él figuran La lozana andaluza (1528) de Francisco Delicado (1475-1535), el Raggionamenti (1534) de Pietro Aretino (1492-1556), La Zaffetta (1532) y La puttana errante (1532) de Lorenzo Venier (1510-1550) o La retorica delle putane (1643) de Ferrante Pallavicino (1615-1644). Como estas obras, Fanny Hill cuenta la vida de una prostituta en la voz de una mujer. La historia de Fanny es la de una pobre huérfana que se ve forzada a entrar al oficio de la prostitución y experimenta en esta profesión todas las vicisitudes, volviéndose una experta en el arte sexual hasta que, al final, se reencuentra con Charles, su primer amor y dueño, se casa y tiene un hijo.

El final de esta obra también presenta un dilema al lector pues es la historia de una prostituta que alcanza prominencia, dinero y estatus. Como en Pamela, la misma historia de "rags to riches" se repite. O, como dice Ann Louise Kibbie (1991), "small town girl makes good" (561). En realidad, Cleland está reescribiendo Pamela (publicada ocho años antes) y proponiendo otra visión de la historia sin el humor de la Shamela de Fielding, pero sí con el realismo crudo de la picaresca. Como ha notado Edward Copeland (1972), "Cleland parodies Pamela [... and] he uses and 
exploits [...] the similarity of the near pornography of Pamela," especialmente en la escena de la violación (344). Más aún, Fanny Hill como contraparte de Pamela parece sugerir que tras vivir una vida disoluta una mujer puede volverse respetable y rica 0 , en otras palabras, que el vicio (y no sólo la virtud) se ve recompensado.

Como en Pamela, en Fanny aparece el motivo de "rags to riches", pero el periplo moral de la protagonista es opuesto al de la heroína de Richardson. Mientras que Pamela se ve recompensada al final por su virtud y se casa con su violador y obtiene su fortuna, Fanny vive una vida "de placer", se casa con su primer amor y dueño (y no su violador) y, además, es ella quien le da a él su fortuna. Críticas como Andrea Haslanger (2011) han considerado que el matrimonio al final de Fanny Hill busca insertar esta novela en el género emergente de la novela sentimental (168). Ann Louise Kibbie (1991) nota cómo la novela intenta “[to] reconcile the sentimental and the mercenary" (567). Es evidente que el final "domesticado" de una prostituta que se vuelve respetable, se casa y tiene un hijo está en sincronía con el de Pamela. El matrimonio resuelve las tensiones sexuales, sociales y de género que se ciernen en la obra. Pamela, sin embargo, fue sancionada por muchos críticos de su tiempo porque mezclaba las clases, al casarse una muchacha pobre con un hombre rico (aunque libertino). Fanny Hill también mezcla las clases, pero el origen del dinero y el rol que tienen el sexo y la corporalidad en la obra son distintos. En la novela Fanny es la mujer económicamente independiente. Ella ha conseguido esa independencia tras comerciar con su cuerpo. Frente a Pamela, Fanny tiene mayor agencia y experiencia, y aunque se “domestique” al final, este personaje no sólo está empoderado por el dinero, sus acciones y su albedrío, sino también por su libertad sexual y literaria.

\section{La reflexividad literaria}

Fanny Hill mezcla el idealismo cervantino propio de la novela sentimental (con su final feliz, "domesticado" y moral) y el realismo de la picaresca femenina (con su prostitución, pobreza y astucia femeninas). Esta obra no sólo reescribe los legados inmediatos de la literatura inglesa, que abrevan de la tradición narrativa europea 
y más específicamente española, sino que también incorpora un alto grado de reflexividad literaria. La reflexividad literaria en Fanny es quijotesca. De la misma manera en que el narrador del Quijote habla del proceso de creación literaria y se queja de las deficiencias de su texto, la narradora Fanny (y el autor Cleland) establece los lineamientos del género narrativo, del pornográfico, y pone en crisis su propia ficción. Hay en esta novela una constante preocupación por escribir buena narrativa y buena pornografía. Más aún, la narradora no sólo establece reglas sino también busca la innovación, es decir, liberar la novela de sus ataduras temáticas y formales.

A lo largo del texto la narradora habla explícitamente de las estrategias narrativas de la pornografía. Al principio dice que va a escribir "the loose part of my life [...] with the same liberty that I led" (Cleland, 2001: 39). En este fragmento hay una correspondencia entre escribir sobre una vida libertina y escribir libremente. Esta mujer no siguió las normas morales de la sociedad; por tanto, su libertinaje (moral, sexual) le permite liberarse de otras ataduras, en este caso de las restricciones formales de la escritura, por ejemplo, de la modestia y del eufemismo. Dice que no es su intención desgarrar la gasa de los ojos de los lectores con violencia o usar disfemismos gratuitos, sino acercarse de manera más fiel a la realidad o "paint situations such as they actually rose to me in nature" (Cleland, 2001: 39). Aquí es evidente la apuesta que hace la novela al realismo. No obstante, como nota David Stevenson (2001), Cleland buscaba en esta obra reescribir L'école des filles, una obra pornográfica francesa del siglo XVII, sin recurrir a palabras groseras (42). El uso que hace la narradora (Cleland) de la alegoría, especialmente de la alegoría mecánica para hablar de la sexualidad, muestra esa constante necesidad de suavizar el lenguaje y, no obstante, de hablar del sexo libremente. ${ }^{4}$

Como el narrador del Quijote, Fanny nota los problemas técnicos o las deficiencias intrínsecas en el acto narrativo y, más específicamente, en la narración pornográfica. Estos problemas, señala, son constantes en obras cuyo tema es el

${ }^{4}$ En la novela hay numerosas referencias al pene como "engine" (cinco veces), "weapon" (cinco veces) o "machine" (24 veces). 
sexo. La narradora sostiene que en cuanto que el sexo es un acto mecánico y repetitivo, su narrativa también lo será. De esa manera Fanny denuncia dentro de su misma obra

the uniformity of adventures and expressions, inseparable from a subject of this sort [...] eternally one and the same [...] there is not escaping a repetition of near the same images, the same figures, the same expressions [...] those pathetic terms [...] in the practice of pleasure, flatten and lose much of their due spirit and energy by the frequency [...] in a narrative of which that practice professedly composes the whole basis. (Cleland, 2001: 129)

En este fragmento la narradora se percata, por un lado, de la mecánica de toda narrativa, y por el otro, del mecanicismo de la pornografía. Si consideramos que en la narrativa del dieciocho hay al menos dos grandes fórmulas narrativas, la novela epistolar sentimental y la episódica de aventuras, es evidente que autores como Cleland se percataron de que había una repetición de motivos o fórmulas. En las novelas sentimentales como Pamela o Clarissa esos motivos repetidos son la carta, los pretendientes, los rechazos, las reconciliaciones, etc. En la novela episódica de aventuras (como Tom fones de Fielding, Zadig de Voltaire o Robinson Crusoe de Defoe) también había un programa: la aparición de un problema, la lucha contra él y la salida con éxito del mismo justo antes de que otro nuevo se presentase. Ésta es la fórmula homérica de la Odisea.

Fanny dilucida la poética del género pues reconoce que la variación y la repetición del mismo motivo e incluso de la misma escena son características fundamentales de la pornografía, es decir, la variación ad infinitum de una escena coital. Uno de los anhelos más constantes del pornógrafo es crear un ars combinatoria que ofrezca una plétora inacabable de escenas sexuales. Como he notado antes, el marqués de Sade en 120 journées de Sodome buscó crear ese ars combinatoria al ofrecer un catálogo de 6oo escenas que incorporaran todas las posibilidades que él concibió y que iban desde el fetiche hasta la coprofilia y la tortura (Deanda-Camacho, 2017: 31). No obstante, como se percató Sade, hay un número limitado de posibili- 
dades sexuales, aunque la imaginación nos prometa otra cosa. Esta limitación es lo que parece irritar a los narradores tanto de 120 journées como de Fanny Hill.

La segunda deficiencia que la narradora nota es más personal y no depende de los lineamientos del género pornográfico. Esta deficiencia aparece como un mea culpa cuando habla de "the revoltingness of gross, rank, and vulgar expressions, and the ridicule of mincing metaphors and affected circumlocutions" (Cleland, 2001: 129). Fanny incluso se disculpa "for having perhaps too much affected the figurative style" (Cleland, 2001: 207). Aquí la narradora se autocritica en el nivel de la forma. Nota una tensión entre el abuso del disfemismo o la grosería y el abuso de la metáfora, la circunlocución y el lenguaje figurado. En esta crítica evidencia que una parte de su programa ha fallado pues, aunque la promesa inicial fue evitar la grosería y contar la historia con liberalidad, al final se percata de que abusó de lo vulgar, la reticencia y las ataduras.

Una de las características que define a Fanny como narradora es que ella asume, a diferencia de Pamela o Clarissa, su rol de escritora. Aunque sólo está escribiendo una carta a una madam, es evidente que se concibe a sí misma como una pornóloga o pornógrafa. De entrada, Fanny destaca su excepcionalidad entre sus coetáneas pues dice que ella goza de "more observation on the characters and manners of the world than what is common to those of my unhappy profession" (Cleland, 2001: 39). Esta virtud la autoriza a escribir y a enseñar a sus lectores su arte de la misma manera que Mrs. Cole, su mentora, se lo enseñó a ella. La finalidad de Fanny es, entonces, contar su despertar sexual, explicar su proceso de maestría en el oficio, pero, sobre todo, narrar la pornografía. Fanny es una prostituta experimentada que instruye al lector en su oficio. Ella conjunta los conocimientos que ha acumulado a lo largo de su vida y que provienen de sus dos mentores: Mrs. Cole, su madam preferida, y su último dueño, el "rational pleasurist.” Éste le enseñó, como ella dice, a conciliar la mente y el cuerpo y "to be sensible that the pleasures of the mind were superior to those of the body" (Cleland, 2001: 211). En suma, Fanny como narradora es consumada, crítica y autorreflexiva.

La autorreflexividad en la obra muestra el legado de la metaficción quijotesca. Si Cervantes analiza su obra a la luz de su audiencia y se disculpa de sus errores, 
Cleland igualmente analiza Fanny Hill como novela y se disculpa por sus errores. Esta reflexividad va más allá de la captatio benevolentiae de la época que busca ganarse la empatía del lector recurriendo a una fórmula retórica. En estos textos hay un verdadero análisis del comportamiento de la ficción, del proceso de creación y de recepción de la escritura. Al hacerlo, Cleland se sincroniza con el Prefacio que Richardson escribió en Clarissa, publicada el mismo año, en el cual reflexiona sobre la obra y la ficción. Como Cleland, Richardson también buscaba justificar sus elecciones narrativas y ofrecer una guía de lectura al lector.

\section{El idealismo de la novela sentimental}

En el Prefacio de Clarissa, Richardson es frontal al admitir que su historia sirve "to investigate the [...] doctrines [...] of morality [... and] Christianity, by showing them thrown into action in the conduct of the worthy characters; while the unworthy [...] are [...] punished" (Richardson, 1985: 34). En esta nota Richardson se dirige a los lectores que criticaron su Pamela por haberla casado con el libertino Mr. B. Al contrario, en Clarissa, la protagonista no se casa con Mr. Lovelace y de esa manera el vicio se encuentra castigado. Asimismo, el autor señala que su novela no busca "to divert and amuse" o ser "light" sino hasta cierto punto "tedious" y un "vehicle for instruction" (Richardson, 1985: 34). Es decir, Richardson declara su intención de hacer de su Clarissa una novela ejemplar en donde el foco se encuentra en el prodesse más que en el delectare. Desde su perspectiva, si el texto es tedioso carece de importancia si la obra es edificante. Más aún, el autor en el prefacio ataca a los lectores que "have objected to the general catastrophe" de su primera y su segunda novelas, y afirma que "the force of an example, ought to be [...] consistent with the design of the whole, and with human nature" (Richardson, 1985: 34).

Richardson parece romper con el idealismo cervantino y orientarse hacia el realismo decimonónico, pues considera que hay que privilegiar la naturaleza humana como modelo. De ese modo, una mujer rica, inteligente y virtuosa como Clarissa no debe casarse con un libertino abusador como Mr. Lovelace. Aunque esto le parezca realista a Richardson, en realidad tal visión reifica el idealismo de 
una sociedad moralista que considera que el vicio siempre se ve castigado. Esta misma aproximación aparece en el Postfacio de Pamela, en el cual el autor ofrece el ejemplo a seguir o no de cada uno de sus personajes. En esta parte Richardson insiste que la historia de Pamela muestra el poder de la providencia cristiana pues puede "turn the most seemingly grievous things to its own glory" (Richardson, 2004: 500). Esta misma lógica aparece en La fuerza de la sangre cuando el narrador al final enfatiza el final feliz de la pareja de Leocadia y su violador, quienes "por muchos y felices años gozaron de sí mismos [...] permitido todo por el cielo" (Cervantes, 2011: 324). Igual que el Rodolfo de Cervantes o el don Juan español redimido, Mr. B. en Pamela a pesar de ser un "fashionable libertine [...] sees his errors, and reforms in the bloom of youth" (Richardson, 2004: 498).

A diferencia de Richardson, en el terreno de la moral, Cleland es ambivalente y aunque dice ofrecer una guía de lectura moral de su obra, es evidente que su guía no sólo es imprecisa sino forzada. Al final de la novela, Fanny dice que el acto de pintar el vicio de manera tan liberal es un sacrificio a la virtud: "I have painted vice in its gayest colours [...] solely in order to make it the worthier, the solemner, sacrifice of it to the virtue" (Cleland, 2001: 224). Esta frase es opaca. En realidad, no hay en la obra ningún sacrificio a la virtud y sí una descripción muy positiva del "vicio", en especial una descripción bastante interesante de la esfera prostibularia londinense. Aunque Fanny Hill dibuja la prostitución como un oficio mediado por un ethos de violencia sexual (de violación, de explotación, etc.), también ofrece a sus lectores una prostituta como modelo femenino de gran independencia económica y elevado estatus social.

La descripción positiva de la prostitución londinense aparece en la novela en dos modelos: la mentora de Fanny, Mrs. Cole, y la misma Fanny. Aunque hay otras dos madamas que encuentra Fanny y que son descritas como ambiciosas y abusivas, ${ }^{5}$ Mrs. Cole es descrita como una "discreet sort of woman" que "contented herself with a moderate living profit upon her industry and had nothing of their

${ }^{5}$ Su primera madam, Mrs. Brown, es descrita como "squob fat, red-faced", y su segunda, Mrs. Jones, aparece como "tall, meager, red-haired, with one of those trivial ordinary faces" (Cleland, 2001: 44, 89). Las dos abusan de Fanny, la venden sin hacerle participar de las ganancias y son ambiciosas. 
greedy rapacious turn [...] a gentlewoman" (Cleland, 2001: 125). El burdel que Mrs. Cole maneja y en el cual Fanny llega al pináculo de su oficio se describe como una "family of love" (Cleland, 2001: 131). En él la protagonista aprende "the economy of the person" pues llega a manejar su cuerpo y su negocio de manera sustentable (Cleland, 2001: 162). El efecto que tiene Mrs. Cole en Fanny es importante ya que se convierte en el modelo de lo que una mujer "de placer" debe hacer. Hacia el final de la novela, después de que Fanny ha heredado su fortuna del "rational pleasurist", se reencuentra con su madam y admira cómo vive en el campo con "a decent pittance" (Cleland, 2001: 289).

El segundo modelo es el de la misma Fanny, quien a pesar de que narra las vicisitudes de ser una prostituta en el Londres de mediados de siglo, al final se vuelve una mujer respetable. Cuando hereda al "rational pleasurist", comienza su ascenso social, renta un piso en Marylebone, contrata una doncella y vive de manera modesta, con "affluence and independence [...] at the head of so large a fortune" (Cleland, 2001: 211). Inmediatamente después, ya casada con Charles, goza de la reputación de ser una "gentlewoman" (Cleland, 2001: 211). Fanny Hill ofrece así un final feliz a la historia de la prostituta. La redención que hace la novela de la mujer "de placer" se inscribe en el idealismo propio de la novela sentimental. No queda claro, sin embargo, si la promoción que experimenta Fanny es validada por la sociedad. Sólo contamos con su narración así que, a diferencia de las verdaderas autobiografías de prostitutas de la época, como las de Harriette Wilson o Julia Johnstone, ignoramos las vicisitudes que pudo encontrar una exprostituta en el medio pequeñoburgués londinense a mediados del siglo XVIII. ${ }^{6}$

\section{El realismo de la picaresca femenina}

Si la descripción positiva de Mrs. Cole y Fanny como modelos femeninos inscriben la novela en el sentimentalismo y el idealismo, es preciso notar cómo Fanny

${ }^{6}$ Sobre los testimonios de verdaderas prostitutas (o cortesanas) en el siglo dieciocho, véanse Robinson (2018) y Wilson (1955). 
crea un contrapeso con una fuerte carga de realismo, denuncia social y crudeza, propios de la picaresca. Aquí me enfoco en la preminencia del lenguaje mercantil en la novela que pone de relieve el factor económico como catalizador de la prostitución. Éste permea en toda la obra, desde las referencias a la pobreza de las mujeres a la administración de sus cuerpos en el oficio. Como han notado Steven Marcus (1985) y Ann Louise Kibbie (1991), hay una constante síntesis en estos textos de lo sexual y lo comercial. Por ejemplo, Fanny cuenta su historia como muchos pícaros, en la cima de su buena fortuna, teniendo "great ease and affluence" pero recuerda cómo fue que vino de "parents extremely poor" (Cleland, 2001: 39). Mientras va de Lancashire a Londres, Emily, su compañera de viaje, infunde en ella la idea de volverse como esas mujeres cuyos "masters [...] had married them, and kept them coaches, and lived vastly grand, and happy, and some, mayhap, came to be duchesses" (Cleland, 2001: 41). A partir de esto Fanny se propone hacer su propio negocio y encuentra en Charles a su primer máster o dueño, quien la "compra" al pagar las deudas contraídas por Fanny con Mrs. Brown. Una vez que él la abandona, Fanny contrae nuevas deudas con Mrs. Jones, las cuales son pagadas por Mr. H., su nuevo dueño. Una vez que Mr. H. la encuentra con su sirviente William en el acto sexual y la abandona, le deja, sin embargo, una indemnización de 50 piezas, con lo cual Fanny gana una independencia temporal y liberadora: "I was not settled in lodgings of my own, abandoned to my own account [...] to sink or to swim [...] in the exercise of my new profession" (Cleland, 2001: 126). Tras aprender lo mejor de su oficio en el burdel de Mrs. Cole, Fanny encuentra un nuevo dueño en Mr. Norbert, "a gentleman originally of a great fortune" quien le deja "a sum far above the state of his fortune" (Cleland, 2001: 166, 179). Finalmente, su riqueza se consolida cuando el "rational pleasurist" la designa como "his sole heiress and executrix" heredándole "a genteel independent settlement" (Cleland, 2001: 212). Al final, ella administra esta fortuna con "prudential economy," lo que le permite "affluence" (Cleland, 2001: 213).

El lenguaje mercantil en la obra vincula constantemente el sexo con el dinero, la transacción sexual con la económica y pone de relieve el realismo de la prostitución, de la pobreza y la desigualdad social y de género. Ya desde Celestina 
(1499) de Fernando de Rojas (1455-1541), críticos como José Antonio Maravall (1968) han enfatizado cómo la tragicomedia, con la introducción de la noción de intercambio económico, inserta en la literatura una dimensión innovadora en la cual se muestran el desarrollo del capitalismo temprano y la expansión mercantil que implicaba la conquista y la explotación de las Indias occidentales.

Del mismo modo, en Fanny Hill, la prevalencia del lenguaje mercantil y las menciones explícitas del dinero desvelan la emergencia del mercantilismo inglés que se aceleraba a mediados del siglo dieciocho. Las numerosas referencias a la máquina y la mecanización preconizan la revolución industrial que sucedería a la vuelta del siglo. Asimismo, Cleland tiene una idea clara del efecto comercial de la pornografía en el mercado editorial. Por tanto, la reflexión que hace Fanny de los lineamientos de la pornografía como un género en el cual se repite con variaciones la misma escena coital predice la forma que tomará este género como fenómeno cultural en el siglo diecinueve. Como apuntan Steven Marcus (1985) y Lynn Hunt (1996), la pornografía del diecinueve es una corriente literaria que se centra en la producción y la distribución masiva de novelas e imágenes. Esta masificación requería la sistematización del género para facilitar la expansión de los mercados literarios y el incremento de la audiencia (que iba desde las clases altas hasta las bajas). La mecanización de la producción editorial exigía la mecanización del género, el cual repetiría hasta el cansancio las mismas fórmulas de representación sexual.

\section{Conclusión}

Fanny Hill desarrolla el género de la novela en sí y el de la novela pornográfica en particular en su transformación de la época premoderna a la época de la reproducción masiva y mecánica. Como dice Lynn Hunt (1996), tanto la novela como la novela pornográfica participan de este proceso de "democratización de la cultura" que expandió mercados y audiencias (13). Fanny Hill junto con otros best sellers de la época rompieron récords de producción y distribución en los mercados nacionales y extranjeros, teniendo un alcance que traspasaba clases sociales y fronteras. Asimismo, esta novela conjunta tanto el idealismo de la novela sentimental como 
el realismo que prefiguró la novela del siglo XIX. Finalmente, esta obra no sólo está en sincronía con las corrientes literarias de la época, sino que reflexiona sobre el mismo quehacer literario, la producción y la recepción narrativas. Estas reflexiones dictarían el quehacer literario de muchos de sus lectores - entre ellos, Sade-. Por estos motivos, conviene considerar Fanny Hill como quijotesca y, por ende, darle su justo espacio en el proceso de canonización de la novela dieciochesca. Al ponerla en contexto con el movimiento de la narrativa en Inglaterra en el siglo XVIII, Fanny Hill emerge como una novela compleja que merece salirse de ese cajón a menudo vilipendiado de la literatura pornográfica.

\section{REFERENCIAS BIBLIOGRÁFICAS}

ARDILA, J. A. G. (2001a). “Cervantes y la Quixotic fiction: sucesión episódica y otros recursos narrativos". Cervantes: Bulletin of the Cervantes Society of America, 21(1), 43-66. https://www.h-net.org/ cervant/csa/articso1/ardila.pdf

ARDILA, J. A. G. (2001b). "La influencia de la narrativa del Siglo de Oro en la novela británica del XVIII". Revista de Literatura, 63(126), 401-423. https://doi. org/10.3989/revliteratura.2001.v63.i126.214

BEASLEY, Jerry. (1976). "Romance and the 'New' Novels of Richardson, Fielding, and Smollet". Studies in English Literature, 1500-1900, 16(3), 437-450. https:// doi.org/10.2307/449725

BORUGHOF, David A. (2016). "Unhappy Endings: La fuerza de la sangre and the Novelas ejemplares of Miguel de Cervantes". Bulletin of Hispanic Studies, 93(5), 461-478. https://doi.org/10.3828/bhs.2016.28

CERVANTES SAAVEDRA, Miguel de. (2011 [1615]). Novelas ejemplares. Madrid: RAE.

CLELAND, John. (2001 [1748]). Fanny Hill or Memoirs of a Woman of Pleasure. Nueva York: Penguin.

COLLINS, Patricia Hill. (2005). Black Sexual Politics. Nueva York: Routledge. 
COPELAND, Edward. (1972). “Clarissa and Fanny Hill: Sisters in Distress.” Studies in the Novel, 4(3), 343-352.

DARNTON, Robert. (1996). The Forbidden Best-sellers of Pre-revolutionary France. Londres: Norton.

DEANDA-CAMAGHO, Elena. (2017). "Quixotic Sade: Echoes of Cervantes in the 120 Days of Sodom". Studies in Eighteenth-Century Culture, 46, 21-33. http://doi. org $/ 10.1353 /$ sec.2017.0004

DEANDA CAMACHO, Elena. (2020). "La pornología como un instrumento epistemológico en Fanny Hill, Thérèse philosophe, el Arte de putear y las Décimas a las prostitutas de México." Cuadernos de Estudios del Siglo XVIII, (30), 137-164. https://doi.org/10.17811/cesxviii.30.2020.137-164

DELFIN VAL, José. (2008). Picaresca femenina. Putarazanas, bujarrones y carnicantores. Madrid: Ámbito.

FRIEDMAN, Edward H. (1987). The Antiheroine's Voice: Narrative Discourse and Transformations of the Picaresque. Columbia: University of Missouri Press.

FRIEDMAN, Edward H. (2006). Cervantes in the Middle: Realism and Reality in the Spanish Novel from Lazarillo de Tormes to Niebla. Newark: Juan de la Cuesta.

HASLANGER, Andrea. (2011). "What Happens When Pornography Ends in Marriage: The Uniformity of Pleasure in Fanny Hill”. English Literary History, $78(1), 163-$ 188.

HAMmOND, Brean S. (1998). "Mid-century English Quixotism and the Defence of the Novel". Eighteenth-Century Fiction, 10(3), 247-268. http://doi.org/10.1353/ ecf.1998.0023

HunT, Lynn. (1996). The Invention of Pornography. Nueva York: Zone Books.

KibBIE, Ann Louise. (1991). "Sentimental Properties: Pamela and Memoirs of a Woman of Pleasure". English Literary History, 58(3), 561-577. https://doi. org/10.2307/2873456

LEFERE, Robin. (1994). "La fuerza de la sangre: historia de una lectura”. RILCE: Revista de Filología Hispánica, 10(2), 63-81. https://hdl.handle.net/10171/4466

MARAVALL, José Antonio. (1968). El mundo social de La Celestina. Madrid: Gredos. 
MARGUS, Steven. (1985). The Other Victorians: A Study of Sexuality and Pornography in Mid-nineteenth Century England. Nueva York: Norton Press.

MAYER, Eric D. (2005). "Self-consuming Narrative: the Problem of Reader Perspective in La fuerza de la sangre". Mester, 34(1), 98-123.https://escholarship. org/uc/item/55ficinz

PARDO GARCíA, Pedro Javier. (1997). La tradición cervantina en la novela inglesa del siglo XVIII. Salamanca: Universidad de Salamanca.

PEAKMAM, Julie. (2003). Mighty Lewd Books. The Development of Pornography in Eighteenth-century England. Londres: Palgrave.

RICHARDSON, Samuel. (1985 [1740]). Pamela. Nueva York: Penguin.

RICHARDSON, Samuel. (2004 [1748]). Clarissa. Nueva York: Penguin.

ROBInson, Mary. (2018). Memoirs of the Late Mrs. Robinson. Sagwan Press.

STAVES, Susan. (1972). "Don Quixote in Eighteenth-century England”. Comparative Literature, 24(3), 193-215. https://doi.org/10.2307/1769895

STEVEnson, David. (2001). "A Note on the Scotsman Who Inspired Fanny Hill". Scottish Studies Review, 2, 39-45.

WATT, Ian. (2001 [1957]). The Rise of the Novel. Berkeley: University of California Press.

WILSON, Harriette. (1955). Harriette Wilson's Memoir. Nueva York: Simon y Schuster.

ZAFRA, Enriqueta. (2009). Prostituidas por el texto: Discurso prostibulario en la picaresca femenina. West Lafayette: Purdue University Press. 